\title{
ACTH-independent Cushing's syndrome with bilateral cortisol-secreting adrenal adenomas: a case report and review of literatures
}

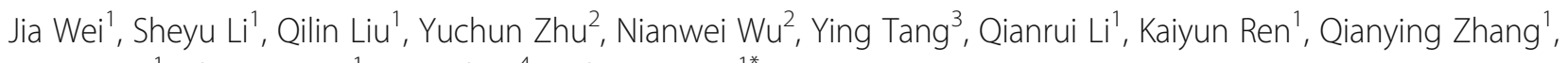
Yerong $\mathrm{Yu}^{1}$, Zhenmei $\mathrm{An}^{1}$, Jing $\mathrm{Chen}^{4}$ and Jianwei $\mathrm{Li}^{1^{*}}$

\begin{abstract}
Background: Adrenocorticotropic hormone (ACTH)-independent Cushing's syndrome (CS) with bilateral cortisolsecreting adenomas has been rarely reported in the literatures. Precise recognition and management of this disorder constitute a challenge to clinicians due to the difficulty of exact location of the functional lesions.

Case presentation: We herein report a new case of a Chinese female patient with a complaint of exertional dyspnea for over 10 years. ACTH-independent CS was diagnosed based on undetectable ACTH and unsuppressed cortisol levels by dexamethasone. Computed tomography (CT) scan indicated bilateral adrenal masses, and adrenal venous sampling (AVS) adjusted by plasma aldosterone revealed hypersecretion of cortisol from both adrenal glands. Bilateral cortisol-secreting adrenal adenomas were suspected and confirmed by the postoperative pathology in subsequent two-step bilateral laparoscopic adrenalectomy. The symptoms and signs of CS relieved after surgery with continuous glucocorticoid replacement.

Conclusions: AVS adjusted by plasma aldosterone could be a useful technique in diagnosing ACTH-independent CS with bilateral adrenal adenomas prior to surgery. And the aldosterone ratio could be used to confirm the success of adrenal vein cannulation in this situation.
\end{abstract}

Keywords: Bilateral cortisol-secreting adrenal adenomas, Cushing's syndrome, Adrenal venous sampling, Aldosterone

\section{Background}

Cushing's syndrome (CS), which results from prolonged excessive cortisol secretion, is a collection of complicated symptoms and associated with significant morbidity and mortality [1, 2]. Endogenous CS includes ACTH-dependent and ACTH-independent etiologies, the latter accounts for $15 \sim 20 \%$ of the cases and is usually induced by unilateral adrenal adenomas or adrenal carcinomas accompanied by autonomous adrenal cortisol secretion [1]. ACTH-independent CS is occasionally caused by bilateral adrenocortical lesions, including unilateral

\footnotetext{
* Correspondence: jerryli678@yahoo.com

${ }^{1}$ Department of Endocrinology and Metabolism, West China Hospital,

Sichuan University, Chengdu 610041, China

Full list of author information is available at the end of the article
}

functional adenoma with a contralateral non-functional mass, bilateral ACTH-independent macronodular adrenal hyperplasia (AIMAH), bilateral primary pigmented nodular adrenocortical disease (PPNAD), and an extremely rare entity, bilateral adrenocortical tumors [3]. Determining the nature and function of bilateral adrenal masses is always a challenge in clinical practice $[4,5]$. We herein report a new case of a Chinese female patient with ACTH-independent Cushing's syndrome due to bilateral cortisol-secreting adenomas, which was diagnosed through adrenal venous sampling (AVS) adjusted by plasma aldosterone and subsequently confirmed by postoperative pathology. In addition, similar cases in the literatures were briefly summarized for discussion.

(c) The Author(s). 2018 Open Access This article is distributed under the terms of the Creative Commons Attribution 4.0 International License (http://creativecommons.org/licenses/by/4.0/), which permits unrestricted use, distribution, and reproduction in any medium, provided you give appropriate credit to the original author(s) and the source, provide a link to the Creative Commons license, and indicate if changes were made. The Creative Commons Public Domain Dedication waiver (http://creativecommons.org/publicdomain/zero/1.0/) applies to the data made available in this article, unless otherwise stated. 


\section{Case presentation}

A 55-year-old Chinese female was admitted to our hospital complaining of exertional dyspnea for more than 10 years. She had been developing truncal obesity and facial rounding over the past 2 years, without evidence of acne, hirsutism or wide purple striae. The patient had a family history of hypertension and was diagnosed with hypertension 10 years prior to admission, and she had been using irbesartan, metoprolol and nifedipine XR since then. She was also diagnosed with hyperlipidemia and prescribed with statins for 5 years. The patient reported no history of alcohol or drug abuse, in particular, no history of steroid use.

Physical examination on admission showed elevated blood pressure $(164 / 104 \mathrm{mmHg})$ and normal heart rate (74 beats per minute). The patient's height, body weight and waist circumference were $156 \mathrm{~cm}, 51 \mathrm{~kg}$ and $88 \mathrm{~cm}$, respectively, with a body mass index (BMI) of $20.96 \mathrm{~kg} / \mathrm{m}^{2}$. She had a plethoric moon-shaped face, centripetal obesity, buffalo hump, accompanied by ecchymosis and slight edema at both lower limbs. Neurological examination was unremarkable except for slight muscle weakness of the lower-extremities.

Routine laboratory examinations showed normal complete blood cell count and hepatorenal parameters, whereas the level of serum triglyceride was slightly elevated. The fasting plasma glucose level was $7.33 \mathrm{mmol} / \mathrm{L}$, and glycosylated hemoglobin (HbA1c) was 6.6\% (Table 1). Endocrinological examinations showed that circadian rhythm of cortisol disappeared, and the level of ACTH was less than $1.00 \mathrm{ng} / \mathrm{L}$ (Table 2). Twenty-four-hour urine free cortisol (24 h UFC) elevated to $634.8 \mu \mathrm{g} / 24 \mathrm{~h}$ (reference range: $20.26-127.55 \mu \mathrm{g} /$ $24 \mathrm{~h})$. The next morning (8 a.m.) serum cortisol level after an overnight $1 \mathrm{mg}$ dexamethasone suppression test (DMST) was $787.5 \mathrm{nmol} / \mathrm{L}$, indicated lack of normal suppression (Table 2). The diagnosis of ACTH-independent Cushing's syndrome was therefore established.

For differential diagnosis, aldosterone-to-renin ratio (ARR) was measured after discontinuation of irbesartan and nifedipine XR for at least 2 weeks as they might lead to false-negative result. Plasma and urinary catecholamine concentrations were detected as well. The diagnosis of primary aldosteronism (PA) was excluded since both plasma renin activity (PRA) and aldosterone concentration (PAC) were within normal limits along with an ARR value of $2.59 \mathrm{ng} / \mathrm{dL}: \mathrm{ng} / \mathrm{mL}$.h. Pheochromocytoma was also ruled out based on laboratory findings (Table 1).

Three adrenal nodules were found with adrenal contrastenhanced CT. One on the right side was $2.5 \mathrm{~cm}$ in diameter, and the other two on the left side with diameters of $2.3 \mathrm{~cm}$ and $0.6 \mathrm{~cm}$, respectively (Fig. 1). Magnetic resonance imaging (MRI) of sellar region revealed normal findings. Bone mineral density measured by dual-energy X-ray absorptiometry scans showed that the $\mathrm{T}$ score of lumbar
Table 1 Laboratory characteristics at the first admission and 1 year after bilateral adrenalectomy

\begin{tabular}{|c|c|c|c|}
\hline & $\begin{array}{l}\text { First } \\
\text { admission }\end{array}$ & $\begin{array}{l}\text { One year after } \\
\text { operation }\end{array}$ & $\begin{array}{l}\text { Reference } \\
\text { values }\end{array}$ \\
\hline$\overline{W B C}\left(10^{9} / L\right)$ & 8.44 & 8.75 & $3.5-9.5$ \\
\hline $\mathrm{Hb}(\mathrm{g} / \mathrm{L})$ & 127 & 124 & $115-150$ \\
\hline Plt $\left(10^{9} / \mathrm{L}\right)$ & 195 & 262 & $100-300$ \\
\hline Glu (mmol/L) & 7.33 & 4.77 & 3.9- 5.9 \\
\hline $\mathrm{ALT}(\mathrm{IU} / \mathrm{L})$ & 30 & 23 & $<40$ \\
\hline AST (IU/L) & 35 & 27 & $<35$ \\
\hline Cre (umol/L) & 52.0 & 48.0 & $37.0-110.0$ \\
\hline BUN (mmol/L) & 6.05 & 4.60 & $3.13-8.17$ \\
\hline LDL-c (mmol/L) & 3.29 & 1.58 & $<4.0$ \\
\hline TG (mmol/L) & 1.95 & 1.15 & $0.29-1.83$ \\
\hline $\mathrm{K}(\mathrm{mmol} / \mathrm{L})$ & 3.63 & 4.04 & $3.5-5.3$ \\
\hline $\mathrm{Na}(\mathrm{mmol} / \mathrm{L})$ & 145.5 & 144.4 & 137.0- 147.0 \\
\hline HbA1c (\%) & 6.6 & 6.0 & $4.5-6.1$ \\
\hline BNP (pg/ml) & 813 & 168 & $0-334$ \\
\hline cTnT (ng/L) & 18.4 & 12.1 & $0-14$ \\
\hline CK-MB (ng/mL) & 6.20 & 5.40 & $<2.88$ \\
\hline Aldosterone (ng/dL) & 17.15 & - & $9.8-27.5$ \\
\hline PRA (ng/mL.h) & 6.62 & - & $0.93-6.56$ \\
\hline ARR (ng/dL: ng/mL.h) & 2.59 & - & - \\
\hline Plasma norepinephrine (ng/L) & 152 & - & $174-357$ \\
\hline Plasma epinephrine (ng/L) & 76 & - & 60- 104 \\
\hline $\begin{array}{l}\text { Urinary norepinephrine } \\
(\mu \mathrm{g} / 24 \mathrm{~h})\end{array}$ & 8.68 & - & $16.3-41.5$ \\
\hline Urinary epinephrine ( $\mu \mathrm{g} / 24 \mathrm{~h})$ & 3.21 & - & 7.5-21.9 \\
\hline
\end{tabular}

$A L T$ alanine aminotransferase, ARR aldosterone-to-renin ratio, AST aspartate transaminase, $B N P$ brain natriuretic peptide, $B U N$ blood urea nitrogen, $C K-M B$ creatine kinase-MB, Cre creatinine, $c T n T$ cardiac troponin T, Glu glucose, $\mathrm{Hb}$ hemoglobin, $H b A 1 c$ glycosylated hemoglobin, $K$ potassium, $L D L-c$ low-density lipoprotein cholesterol, $\mathrm{Na}$ sodium, Plt platelet, PRA plasma renin activity, TG triglyceride, WBC white blood cell count

spine, femoral neck and the total hip was $-3.0,-3.2$ and -3.3 , respectively, which indicated osteoporosis. In order to locate the functional lesions in this patient, AVS was performed and the concentrations of plasma aldosterone and cortisol were measured from both adrenal veins (AV) and inferior vena cava (IVC). Adrenal venous catheterization was successful, and the hormone levels were shown in Table 3. The adrenal vein to inferior vena cava cortisol (AV: IVC) gradient was 13.57 on the right side and 13.88 on the left side. The left and right AV to IVC gradient of aldosterone were 5.58 and 6.79 respectively. Moreover, the cortisol/aldosterone ratio (CAR) in adrenal veins was 292.52 on the right and 359.29 on the left, along with a left-to-right odds ratio of 1.23 (Table 3). In combination with the results of AVS, which indicated non-lateralization, this patient was diagnosed with CS induced by bilateral adrenal excessive cortisol secretion. 
Table 2 Results of hormone levels and dexamethasone suppression tests

\begin{tabular}{lllllll}
\hline & & $08: 00$ ACTH (ng/L) & 24 h UFC (ug/24 h) & $24: 00$ PTC (nmol/L) & 08:00 PTC (nmol/L) & $\begin{array}{l}\text { 08:00 PTC the next } \\
\text { day (nmol/L) }\end{array}$ \\
\hline Before operation & Baseline & $<1.0$ & 634.8 & 716.0 & 858.4 & - \\
& $1 \mathrm{mg}$ ODMST & - & - & - & 767.0 & 787.5 \\
After right adrenalectomy & Baseline & $<1.0$ & 40.8 & 202.1 & 223.9 & - \\
& $1 \mathrm{mg}$ ODMST & - & - & - & 211.6 & 290.1 \\
\hline
\end{tabular}

ACTH adrenocorticotropic hormone, ODMST overnight dexamethasone suppression test, PTC plasma total cortisol, $24 \mathrm{~h}$ UFC $24 \mathrm{~h}$ urine free cortisol

\section{Treatment and follow-up}

The patient was treated with metoprolol succinate, rosuvastatin, insulin, calcium and vitamin D supplements during the investigation. Considering her poor cardiac function, a two-step operation was planned. Laparoscopic right adrenalectomy was performed, followed by left adrenalectomy after a two-month interval. Pathological findings of the removed right adrenal mass indicated a yellow adenoma with $2.5 \mathrm{~cm}$ in diameter, surrounded by atrophic adrenal tissue (Fig. 2).

Overnight $1 \mathrm{mg}$ DMST was repeated 2 weeks after surgery, which demonstrated no inhibition on the serum cortisol at 8 a.m. on the following day, despite significantly decreased cortisol level post-operation (Table 2). Therefore, it can be inferred that the autonomous cortisol secretion from left adrenal masses was persistent. The left adrenal gland was then removed and two adenomas were confirmed by pathological examination (Fig. 2). The 8 a.m. plasma cortisol after 3 days of bilateral adrenalectomy was $37.30 \mathrm{nmol} / \mathrm{L}$. Hydrocortisone replacement therapy (from $20 \mathrm{mg}$ t.i.d to $20 \mathrm{mg}$ q.d.) was administered after surgery. At 1 year after the operations, the patient lost $4 \mathrm{~kg}$ of body weight and the waist circumference reduced to $71 \mathrm{~cm}$.

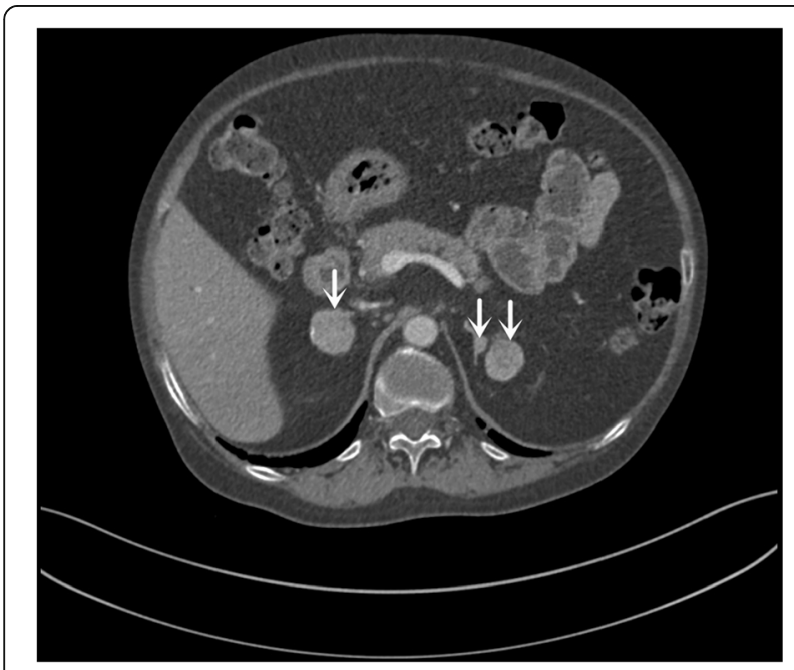

Fig. 1 Adrenal computed tomography $(C T)$ of the patient. Adrenal $\mathrm{CT}$ showed a right adrenal nodule with a diameter of $2.5 \mathrm{~cm}$, and two left nodules with diameters of $2.3 \mathrm{~cm}$ and $0.6 \mathrm{~cm}$, respectively (arrows)
Changes of other laboratory examinations at the last follow-up compared with the first admission were shown in Table 1.

\section{Literature review}

An electronic literature search in PubMed was performed to screen the case reports relating to ACTHindependent Cushing's syndrome caused by bilateral cortisol-secreting adenomas. Searching words included "Cushing's syndrome" and "bilateral adrenocortical adenoma”. All reference lists from the main reports and relevant reviews were screened manually for additional eligible studies. The results were limited to full-text articles published in English. Extracted data included the first author's name, year of publication, country, preoperative diagnostic technique, patient characteristics (gender, age at onset and at diagnosis), lesions size, operative method and tumor cut surface.

A total of 231 papers were identified, of which, 15 available reports were included in the review (Fig. 3). The clinical features in these patients were summarized as following: 1) this disorder seemed predominated in females (male: female ratio 1: 14), with an adult onset (the mean age was $39.6 \pm 8.6$ years; ranged from 24 to 53 years); 2) the size of bilateral adrenal adenomas ranged from 1.0 to $5.0 \mathrm{~cm}$ in diameter, the majority of which were solitary in both sides (12 out of $15,80 \%) ; 3$ ) most of the bilateral adrenal lesions were found to occur synchronously, except that three cases occurred at different periods $[6,7]$; 4) the surrounded adrenal cortex of resected adenomas was atrophic in most cases; 5)

Table 3 Results of adrenal venous sampling

\begin{tabular}{lllll}
\hline & $\begin{array}{l}\text { Aldosterone } \\
(\mathrm{ng} / \mathrm{dL})\end{array}$ & $\begin{array}{l}\text { Cortisol } \\
(\mathrm{nmol} / \mathrm{L})\end{array}$ & $\begin{array}{l}\text { Cortisol/ } \\
\text { Aldosterone } \\
\text { ratio }\end{array}$ & $\begin{array}{l}\text { Lateralization } \\
\text { ratio }\end{array}$ \\
\hline $\begin{array}{l}\text { Left adrenal } \\
\text { vein }\end{array}$ & 27.73 & 9963 & 359.29 & 1.23 \\
$\begin{array}{l}\text { Right adrenal } \\
\text { vein }\end{array}$ & 33.29 & 9738 & 292.52 & - \\
$\begin{array}{l}\text { Inferior vena } \\
\text { cava }\end{array}$ & 4.97 & 717.6 & - & - \\
$\begin{array}{l}\text { AV: IVC ratio } \\
\text { (left/right) }\end{array}$ & $5.58 / 6.79$ & $13.88 / 13.57$ & - & - \\
\hline
\end{tabular}

$A V$ adrenal vein, IVC inferior vena cava 

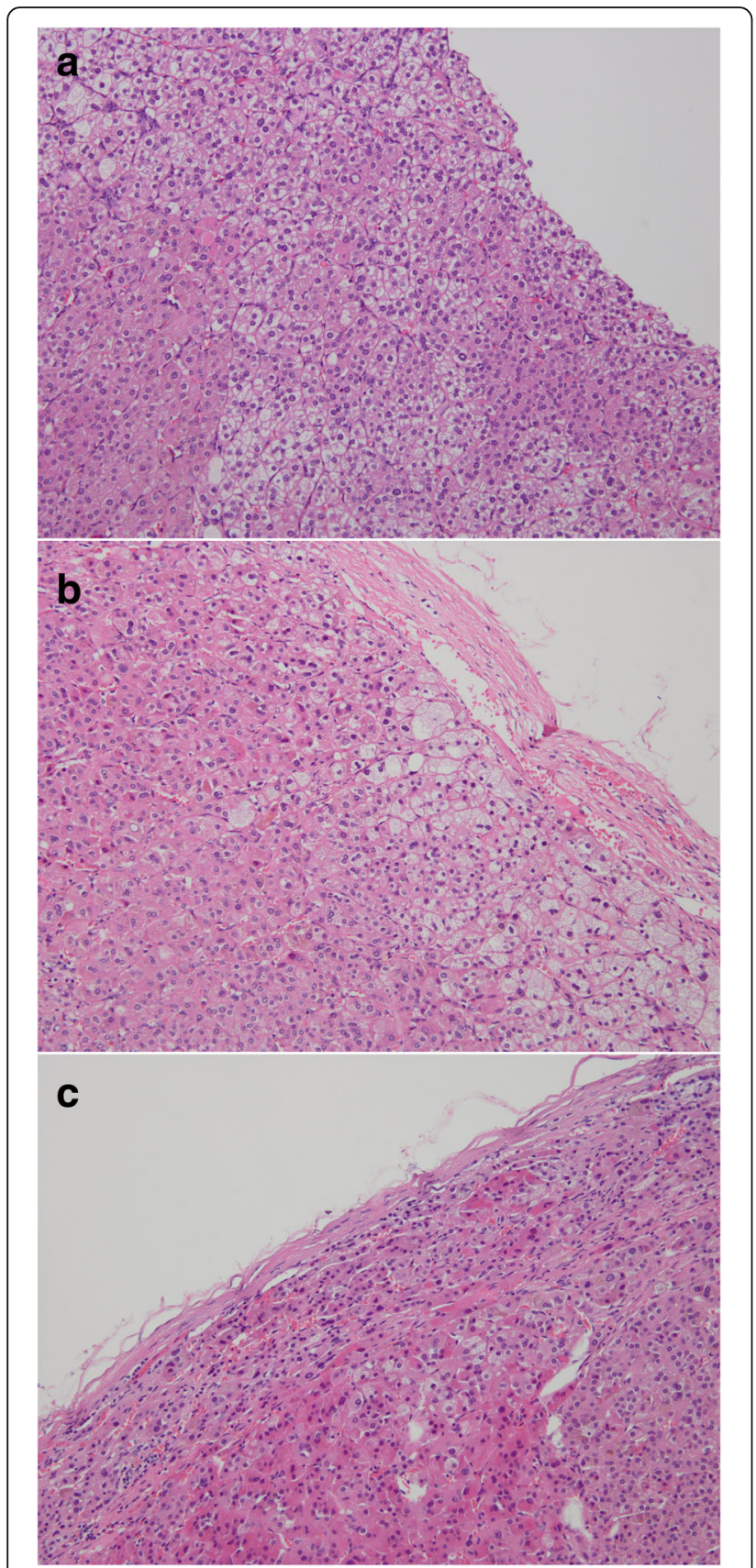

Fig. 2 Pathological findings of the resected adrenal glands. Pathological examination of the right (a) and left adrenal gland $(\mathbf{b}$ and $\mathbf{c})$ indicated bilateral adrenal adenomas (HE stain, $\times 200$ )

although no recurrence was reported postoperatively, long-term outcomes remain unclear with the longest follow-up duration of 123 months [8] (Table 4).

All preoperative diagnoses were established based on endocrinological studies and imaging findings, while the methods used to determine the functional lesions were different. Nine patients underwent adrenocortical scintigraphy with different radio-imaging agents, all of which revealed bilateral adrenal uptake. AVS was performed in eight cases to evaluate the hypersecretion of cortisol, and only two of them applied cortisol gradient adjusted by plasma aldosterone $[9,10]$. All patients underwent surgical resection of adenomas, including ten bilateral total adrenalectomy [6, 11-19], three unilateral partial adrenalectomy with contralateral total adrenalectomy $[9,10,20]$, one bilateral partial adrenalectomy [21] and one bilateral subtotal adrenalectomy [22]. All patients received glucocorticoid replacement therapy postoperatively. It is noteworthy that glucocorticoid therapy was reported to be withdrawn during follow-up in patients who underwent bilateral subtotal adrenalectomy or partial adrenalectomy [21-23].

\section{Discussion and conclusion}

ACTH-independent Cushing's syndrome with bilateral cortisol-secreting adenomas has been rarely reported in the literature [6, 8-24]. This disorder should be differentiated from PPNAD, AIMAH and unilateral functional adenoma with contralateral non-functional lesion for the determination of therapeutic regimen. PPNAD is characterized by multiple small pigmented nodules of hyperplastic adrenocortical cells and cortical atrophy with an early age of onset [25]. AIMAH, in which the bilateral enlarged adrenal glands with numerous nodules larger than $1 \mathrm{~cm}$ in diameter lead to an irregular contour on CT or MRI, is associated with aberrant expression of hormone receptors and can be treated by appropriate antagonist [26, 27]. The definite diagnosis of AIMAH or PPNAD depends on histo-pathology. Although the clinical characters of some similar cases were identified by several previous studies, precise diagnosis and treatment of patients with bilateral $\mathrm{ACTH}$-independent adrenal adenomas remain challenging $[8,23,24]$.

The diagnostic value of AVS and ${ }^{131}$ I- $6 \beta$-iodomethyl19-norcholesterol ( $\left.{ }^{131} \mathrm{I}-\mathrm{NP}-59\right)$ scintigraphy for defining the hormone-secreting status in adrenocortical diseases was well established [28-30]. NP-59, which was clinically available in 1975 and most frequently used, can be accumulated by functioning adrenal cortical tissues as radiolabeled cholesterol analog [31]. The uptake of NP-59 would reflect the anatomic localization and functional characterization of adrenal masses accordingly. Since the ${ }^{131}$ I-NP-59 scintigraphy is unavailable in most hospitals in China and many other countries, an alternative technique is needed for the diagnosis.

AVS has been recommended over the past 10 years by international guidelines to differentiate unilateral from bilateral primary aldosteronism through cortisol-corrected aldosterone ratio [30, 32, 33]. During AVS, blood was collected from bilateral AV and IVC or peripheral vein (PV) to measure aldosterone and cortisol levels, and the comparison of AV and IVC cortisol concentration was further used to assess whether successful cannulation was achieved in PA. In this case, we used the AV: IVC aldosterone ratio 


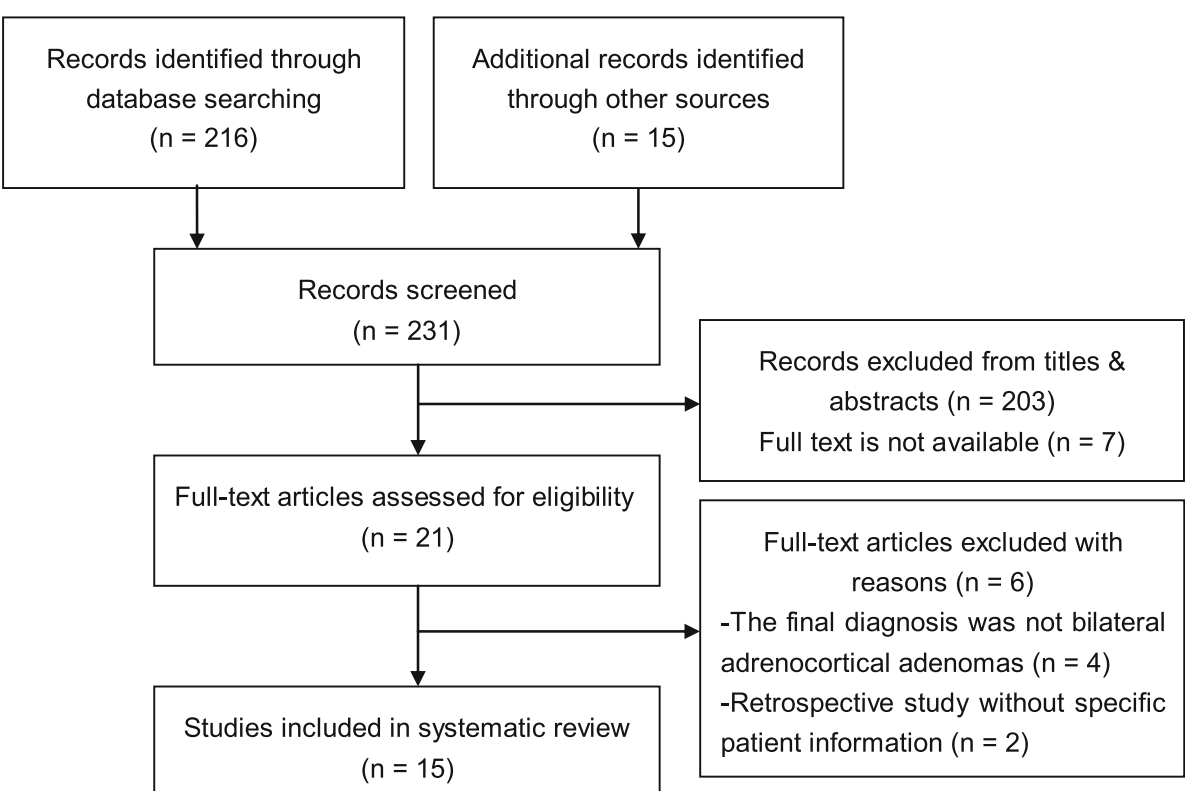

Fig. 3 Flowchart of study selection for the literature review

to assess the successfulness of catheter insertion since the aldosterone concentration could remain stable during the sampling. There were some researches in which adrenaline concentration was measured to evaluate catheterization accuracy, however, catheterization process itself might lead to stress-induced fluctuation of adrenaline and further result in misjudgment $[17,34]$. Even though there is still no general agreement on the definition of catheterization success in AVS, aldosterone concentration instead of adrenaline could be a robust assay for this purpose, after the aldosterone overproduction being excluded.

We used AV: IVC cortisol ratio in both side and left-toright CAR gradient to differentiate unilateral from bilateral cortisol overproduction. Young et al. [8] suggested that if the cortisol gradient of AV to PV or IVC was greater than 6.5, cortisol-secreting adenoma should be considered. Although the accuracy and applicability remain to be proved due to the lack of research in this area, we can at least assume that a larger ratio represents a greater likelihood of spontaneous cortisol secretion. The authors also proposed cutoff values of high- to low-side AV cortisol gradient ratio to determine the lateralization of cortisol hypersecretion, and suggested that predominant cortisol secretion was considered if the cortisol lateralization ratio was $\geq 2.3$ [8]. However, unadjusted cortisol lateralization ratio might confound the interpretation of AVS results because of the cortisol concentration was 1.8 times higher in the right AV than in the left side, which was the result of dilution effect [35]. Since PA was ruled out in this patient, the correction was considered to be achieved through aldosterone in this setting. It should be noted, however, that AVS cannot be used to differentiate the functional status of each mass in the left adrenal gland.

AVS is generally safe, with a very low risk of adverse events. The rate of adrenal venous rupture, one of the main complications, was reported as $0.61 \%$ in a recent international multicenter study [36]. Adrenal vein thrombosis, infarction and perforation, and subsequent periadrenal hemorrhage and hematoma have been also reported in the literature [37]. In consideration of the risk of failure and complications, experienced radiologists were suggested for this invasive procedure. In this case, no adverse event was observed throughout the duration of treatment and follow-up.

The optimal treatment for patients with bilateral cortisol-secreting adenomas remains uncertain [27, 38]. Two-step bilateral adrenalectomy was performed on our patient and resulted in remarkable remission of hypercortisolism, and further confirmed the cortisol-secreting feature of each adrenal mass. Even though lifelong steroid supplementation was required, the quality of her life improved considerably. However, lifelong follow-up of the patient is required regarding to the unclear long-term outcome of bilateral adrenalectomy in this disease [39, 40]. Recently, partial adrenalectomy (removal of the adenomas only) was performed in some similar cases, in which functional recovery of hypothalamic-pituitary-adrenal axis could be achieved after surgery, while further studies for prognosis are still warranted [9, 20, 21, 23].

In summary, we reported a Chinese female patient with ACTH-independent CS caused by bilateral cortisol-secreting adenomas. She was diagnosed through aldosterone-adjusted 
Table 4 The available case reports of CS with bilateral adrenal adenomas

\begin{tabular}{|c|c|c|c|c|c|c|c|}
\hline \multirow[t]{2}{*}{ Study ID } & \multirow[t]{2}{*}{ Country } & \multicolumn{2}{|l|}{ Age (years) } & \multirow[t]{2}{*}{ Gender } & \multicolumn{2}{|c|}{ Lesions size $(\mathrm{cm})$} & \multirow[t]{2}{*}{ Preoperative diagnostic technique } \\
\hline & & Onset & Diag. & & right & left & \\
\hline 1963 Chappell, AG. & NM & 43 & 47 & Female & $3.0,1.5$ & 3.0 & Left AVS and clinical manifestation \\
\hline 1985 Mimou N. & Japan & NM & 43 & Female & 2.0 & 2.5 & $\begin{array}{l}\text { AVS without correction and Adrenocortical } \\
\text { scintigraphy with }{ }^{75} \text { Se-Scintadren }\end{array}$ \\
\hline 1995 Dinneen SF. & America & 49 & 69 & Female & 3.1 & 2.1 & AVS without correction \\
\hline 1997 Makino, S. & Japan & 35 & 45 & Female & $2.5,2.0$ & 2.4 & Adrenocortical scintigraphy with ${ }^{131}$-adosterol \\
\hline 1997 Tamura, H. & Japan & 43 & 48 & Female & 3.5 & 2.4 & Adrenocortical scintigraphy with ${ }^{131}$-adosterol \\
\hline 2003 Nomura, K. & Japan & 33 & 37 & Female & 1.8 & 1.6 & Adrenocortical scintigraphy with ${ }^{131} \mid-N P-59$ \\
\hline 2004 Tung SC. & Taiwan & 24 & 33 & Female & 3.0 & 3.0 & Adrenocortical scintigraphy with ${ }^{131}$ I-NP-59 \\
\hline 2006 Desai, N. & America & 30 & 30 & Female & 2.0 & 3.0 & lodocholesterol scan \\
\hline 2006 Inoue T. & Japan & 39 & 41 & Female & 2.0 & 2.4 & Adrenocortical scintigraphy \\
\hline 2007 Domino, JP. & Singapore & NM & 35 & Female & 1.8 & 2.2 & AVS adjusted by aldosterone \\
\hline 2008 Oki, Kl. & Japan & 35 & 50 & Female & 1.1 & 1.0 & $\begin{array}{l}\text { AVS adjusted by aldosterone and Adrenocortica } \\
\text { scintigraphy with }{ }^{131} 1 \text {-adosterol }\end{array}$ \\
\hline 2012 Martins, RG. & UK & 51 & 59 & Female & 2.8 & 2.6 & AVS without correction \\
\hline $2013 \mathrm{Ku}, \mathrm{EJ}$. & Korea & 45 & 48 & Female & 2.8 & $2.3,1.7$ & AVS without correction \\
\hline 2014 Yasuda, A. & Japan & 53 & 63 & Male & 2.4 & 2.5 & $\begin{array}{l}\text { AVS without correction and Adrenocortical } \\
\text { scintigraphy with }{ }^{131} \mid \text {-adosterol }\end{array}$ \\
\hline 2015 Monno, S. & Japan & 35 & 39 & Female & 2.4 & 3.1 & Adrenocortical scintigraphy with ${ }^{131}$ I-NP-59 \\
\hline \multirow[t]{2}{*}{ Study ID } & \multirow{2}{*}{\multicolumn{2}{|c|}{ Operation }} & \multicolumn{2}{|c|}{ Cut surface } & & & \multirow[t]{2}{*}{ Functional side } \\
\hline & & & \multicolumn{2}{|l|}{ right } & \multicolumn{2}{|l|}{ left } & \\
\hline 1963 Chappell, AG. & \multicolumn{2}{|c|}{$\begin{array}{l}\text { Left, right total adrenalectomy } \\
(2 \text { months later) }\end{array}$} & \multicolumn{2}{|c|}{ Yellow } & \multicolumn{2}{|l|}{ NM } & NM \\
\hline 1985 Mimou N. & \multicolumn{2}{|c|}{ Bilateral total adrenalectomy } & \multicolumn{2}{|c|}{ Dark brown } & \multicolumn{2}{|c|}{ Brownish-yellow } & Bilateral adenomas \\
\hline 1995 Dinneen SF. & \multicolumn{2}{|c|}{ Bilateral total adrenalectomy } & \multicolumn{2}{|l|}{ NM } & \multicolumn{2}{|l|}{ NM } & Bilateral adenomas \\
\hline 1997 Makino, S. & \multicolumn{2}{|c|}{ Bilateral total adrenalectomy } & \multicolumn{2}{|c|}{ Yellow, Black } & \multicolumn{2}{|l|}{ Yellow } & Left adenoma, the black right adenoma \\
\hline 1997 Tamura, H. & \multicolumn{2}{|c|}{ Bilateral total adrenalectomy } & \multicolumn{2}{|c|}{ Brown } & \multicolumn{2}{|l|}{ NM } & Bilateral adenomas \\
\hline 2003 Nomura, K. & \multicolumn{2}{|c|}{ Bilateral subtotal adrenalectomy } & Black & & Black & & Bilateral adenomas \\
\hline 2004 Tung SC. & $\begin{array}{l}\text { Right, left t } \\
\text { (9 years lat }\end{array}$ & nalectomy & Yellow & & Yellow & & Bilateral adenomas \\
\hline 2006 Desai, N. & Bilateral tot & alectomy & Yellow & & Yellow/ & & Bilateral adenomas \\
\hline 2006 Inoue T. & Bilateral pa & nalectomy & Yellow & -brown & Yellowis & -brown & Bilateral adenomas \\
\hline 2007 Domino, JP. & $\begin{array}{l}\text { Right total } \\
\text { partial adre }\end{array}$ & $\begin{array}{l}\text { ctomy, left } \\
\text { ny }\end{array}$ & NM & & NM & & Bilateral adenomas \\
\hline 2008 Oki, Kl. & $\begin{array}{l}\text { Left partial } \\
\text { total adren }\end{array}$ & ctomy, right & Golder & yellow & NM & & Bilateral adenomas \\
\hline 2012 Martins, RG. & Bilateral tot & alectomy & NM & & NM & & Bilateral adenomas \\
\hline $2013 \mathrm{Ku}, \mathrm{EJ}$. & Bilateral tot & alectomy & Brown & & Light br & & Bilateral adenomas \\
\hline 2014 Yasuda, A. & $\begin{array}{l}\text { Left total a } \\
\text { partial adre }\end{array}$ & $\begin{array}{l}\text { tomy, right } \\
\text { ny }\end{array}$ & NM & & NM & & Bilateral adenomas \\
\hline 2015 Monno, S. & $\begin{array}{l}\text { Left, right t } \\
\text { (3 months }\end{array}$ & enalectomy & Yellow & & Golden & & Bilateral adenomas \\
\hline
\end{tabular}

AVS adrenal venous sampling, CS Cushing's syndrome, NM not mentioned, ${ }^{75}$ Se-Scintadren 6-methyl ${ }^{75}$ Se-selenomethyl-19-norcholeste-5(10)-en-3ß-ol,

${ }^{131}$ I-NP-59 ${ }^{131}$ 1-6ß-iodomethyl-19-norcholesterol

AVS and successfully treated with bilateral adrenalectomy. It confirmed that selective AVS with aldosterone-corrected cortisol ratio could be a useful technique to evaluate the cortisol-secreting function of each adrenal mass and further guide therapeutic decision-making. Owing to the existing dispute over the interpretation of the AVS results, the definite cut-off values for lateralization of cortisol hypersecretion requires further confirmation. 


\begin{abstract}
Abbreviations
${ }^{131}$ I-NP-59: ${ }^{131}$ I-6ß-iodomethyl-19-norcholesterol; 24 h UFC: Twenty-four-hour urine free cortisol; ACTH: Adrenocorticotropic hormone; AIMAH: ACTHindependent macronodular adrenal hyperplasia; ARR: Aldosterone-to-renin ratio; AV: Adrenal vein; AVS: Adrenal venous sampling; BMI: Body mass index; BNP: Brain natriuretic peptide; CAR: Cortisol to aldosterone ratio;

CS: Cushing's syndrome; CT: Computed tomography; DMST: Dexamethasone suppression test; HbA1c: Glycosylated hemoglobin; IVC: Inferior vena cava; MRI: Magnetic resonance imaging; PA: Primary aldosteronism; PAC: Plasma aldosterone concentration; PPNAD: Primary pigmented nodular adrenocortical disease; PRA: Plasma renin activity; PV: Peripheral vein
\end{abstract}

\section{Availability of data and materials}

All data generated or analyzed during this study are included in this published article.

\section{Authors' contributions}

JW and SL diagnosed and treated the patient, reviewed the literature and drafted the manuscript. YZ and NW performed the surgery and helped draft the manuscript. YT carried out the pathological diagnosis and helped draft the manuscript. QLiu, QLi, KR, QZ, YY and ZA participated in the clinical diagnosis and treatments, and helped draft the manuscript. JL and JC critically revised the manuscript. All of the authors read and approved the final manuscript.

\section{Ethics approval and consent to participate} Not applicable.

\section{Consent for publication}

Written informed consent for publication of the patient's clinical details and clinical images was obtained from the patient.

\section{Competing interests}

The authors declare that they have no competing interests.

\section{Publisher's Note}

Springer Nature remains neutral with regard to jurisdictional claims in published maps and institutional affiliations.

\section{Author details}

${ }^{1}$ Department of Endocrinology and Metabolism, West China Hospital, Sichuan University, Chengdu 610041, China. ${ }^{2}$ Department of Urology, West China Hospital, Sichuan University, Chengdu 610041, China. ${ }^{3}$ Department of Pathology, West China Hospital, Sichuan University, Chengdu 610041, China. ${ }^{4}$ Department of Pathology, Immunology, and Laboratory Medicine, University of Florida, Gainesville, FL 32610, USA.

Received: 26 December 2017 Accepted: 16 April 2018 Published online: 23 April 2018

\section{References}

1. Newell-Price J, Bertagna X, Grossman AB, Nieman LK. Cushing's syndrome. Lancet. 2006;367(9522):1605-17.

2. Graversen D, Vestergaard P, Stochholm K, Gravholt $\mathrm{CH}$, Jorgensen JO. Mortality in Cushing's syndrome: a systematic review and meta-analysis. Eur J Intern Med. 2012;23(3):278-82.

3. Lacroix A, Bourdeau I. Bilateral adrenal Cushing's syndrome: macronodular adrenal hyperplasia and primary pigmented nodular adrenocortical disease. Endocrinol Metab Clin N Am. 2005;34(2):441-58.

4. Doppman JL. The dilemma of bilateral adrenocortical nodularity in Conn's and Cushing's syndromes. Radiol Clin N Am. 1993;31(5):1039-50.

5. Maghrabi A, Yaqub A, Denning KL, Benhamed N, Faiz S, Saleem T. Challenges in the diagnostic work-up and management of patients with subclinical Cushing's syndrome and bilateral adrenal masses. Endocr Pract. 2013;19(3):515-21.

6. Tung SC, Wang PW, Huang TL, Lee WC, Chen WJ. Bilateral adrenocortical adenomas causing ACTH-independent Cushing's syndrome at different periods: a case report and discussion of corticosteroid replacement therapy following bilateral adrenalectomy. J Endocrinol Investig. 2004;27(4):375-9.

7. Imai T, Funahashi H, Tanaka Y, Tobinaga J, Wada M, Morita-Matsuyama T, et al. Adrenalectomy for treatment of Cushing syndrome: results in 122 patients and long-term follow-up studies. World J Surg. 1996;20(7):781-6. discussion 786-7

8. Young WF Jr, du Plessis H, Thompson GB, Grant CS, Farley DR, Richards ML, et al. The clinical conundrum of corticotropin-independent autonomous cortisol secretion in patients with bilateral adrenal masses. World J Surg. 2008;32(5):856-62.

9. Domino JP, Chionh SB, Lomanto D, Katara AN, Rauff A, Cheah WK. Laparoscopic partial adrenalectomy for bilateral cortisol-secreting adenomas. Asian J Surg. 2007;30(2):154-7.

10. Oki K, Yamane K, Sakashita Y, Kamei N, Watanabe H, Toyota N, et al. Primary aldosteronism and hypercortisolism due to bilateral functioning adrenocortical adenomas. Clin Exp Nephrol. 2008;12(5):382-7.

11. Chappell AG. Cushing's syndrome due to bilateral adrenal adenomata. Proc R Soc Med. 1963;56(3):165-6.

12. Mimou N, Sakato S, Nakabayashi H, Saito Z, Takeda R, Matsubara F. Cushing's syndrome associated with bilateral adrenal adenomas. Acta Endocrinol. 1985;108(2):245-54

13. Dinneen SF, Carney JA, Carpenter PC, Grant CS, Young WF Jr. Acthindependent Cushing's syndrome: bilateral cortisol-producing adrenal adenomas. Endocr Pract. 1995;1(2):77-81.

14. Makino S, Chikazawa H, Yorimitsu A, Suehiro T, Hashimoto K, Ohashi Y, et al. A rare case of Cushing's syndrome due to bilateral adrenocortical adenomas. Endocr J. 1997:44(4):533-40.

15. Tamura H, Sugihara H, Minami S, Emoto N, Shibasaki T, Shuto $Y$, et al. Cushing's syndrome due to bilateral adrenocortical adenomas with different pathological features. Intern Med. 1997;36(11):804-9.

16. Desai N, Kapoor A, Singh BK, Liu J. Bilateral adrenal adenomas and persistent leukocytosis: a unique case of Cushing's syndrome. Am J Med. 2006;119(3):e3-5.

17. Martins RG, Agrawal R, Berney DM, Reznek R, Matson M, Grossman AB, et al. Differential diagnosis of adrenocorticotropic hormone-independent Cushing syndrome: role of adrenal venous sampling. Endocr Pract. 2012;18(6):e153-7.

18. Ku EJ, Hong AR, Kim YA, Bae JH, Chang MS, Kim SW. Adrenocorticotropic hormone-independent Cushing syndrome with bilateral cortisol-secreting adenomas. Endocrinol Metab (Seoul). 2013;28(2):133-7.

19. Monno S, Tachikawa T, Maekawa T, Sasano H. A case of Cushing's syndrome due to bilateral cortisol-secreting adenomas with unilateral DHEAS oversecretion. Endocr J. 2015;62(3):283-8.

20. Yasuda A, Seki T, Ito K, Takagi A, Watanabe D, Nakamura N, et al. A rare case of Cushing's syndrome due to bilateral adrenocortical adenomas. Tokai J Exp Clin Med. 2014;39(4):158-65.

21. Inoue T, Ishiguro K, Suda T, Ito N, Suzuki Y, Taniguchi $Y$, et al. Laparoscopic bilateral partial adrenalectomy for adrenocortical adenomas causing Cushing's syndrome: report of a case. Surg Today. 2006;36(1):94-7.

22. Nomura K, Saito H, Aiba M, lihara M, Obara T, Takano K. Cushing's syndrome due to bilateral adrenocortical adenomas with unique histological features. Endocr J. 2003;50(2):155-62.

23. Li Z, Zhu Y, Kong C, Yin L, Gao Z, Zhao W, et al. Corticotropin-independent Cushing's syndrome in patients with bilateral adrenal masses. Urology. 2011 77(2):417-21.

24. Aiba M, Kawakami M, Ito Y, Fujimoto Y, Suda T, Demura H. Bilateral adrenocortical adenomas causing Cushing's syndrome. Report of two cases with enzyme histochemical and ultrastructural studies and a review of the literature. Arch Pathol Lab Med. 1992;116(2):146-50.

25. Horvath A, Stratakis C. Primary pigmented nodular adrenocortical disease and Cushing's syndrome. Arq Bras Endocrinol Metabol. 2007;51(8):1238-44.

26. Albiger NM, Ceccato F, Zilio M, Barbot M, Occhi G, Rizzati S, et al. An analysis of different therapeutic options in patients with Cushing's syndrome due to bilateral macronodular adrenal hyperplasia: a single-centre experience. Clin Endocrinol. 2015;82(6):808-15.

27. Nieman LK, Biller BM, Findling JW, Murad MH, Newell-Price J, Savage MO, et al. Treatment of Cushing's syndrome: an endocrine society clinical practice guideline. J Clin Endocrinol Metab. 2015;100(8):2807-31.

28. Lumachi F, Zucchetta P, Marzola MC, Bui F, Casarrubea G, Angelini F, et al. Usefulness of CT scan, MRI and radiocholesterol scintigraphy for adrenal imaging in Cushing's syndrome. Nucl Med Commun. 2002;23(5):469-73.

29. Builes-Montano CE, Villa-Franco CA, Roman-Gonzalez A, Velez-Hoyos A, Echeverri-Isaza S. Adrenal venous sampling in a patient with adrenal Cushing syndrome. Colomb Med (Cali). 2015;46(2):84-7.

30. Funder JW, Carey RM, Mantero F, Murad MH, Reincke M, Shibata H, et al. The management of primary aldosteronism: case detection, diagnosis, and 
treatment: an endocrine society clinical practice guideline. J Clin Endocrinol Metab. 2016;101(5):1889-916.

31. Sarkar SD, Beierwaltes H, Ice RD, Basmadjian GP, Hetzel KR, Kennedy WP, et al. A new and superior adrenal scanning agent, NP-59. J Nucl Med. 1975; 16(11):1038-42.

32. Nishikawa T, Omura M, Satoh F, Shibata H, Takahashi K, Tamura N, et al. Guidelines for the diagnosis and treatment of primary aldosteronism-the Japan endocrine society 2009. Endocr J. 2011;58(9):711-21.

33. Funder JW, Carey RM, Fardella C, Gomez-Sanchez CE, Mantero F, Stowasser $M$, et al. Case detection, diagnosis, and treatment of patients with primary aldosteronism: an endocrine society clinical practice guideline. J Clin Endocrinol Metab. 2008;93(9):3266-81.

34. Guo YW, Hwu CM, Won JG, Chu CH, Lin LY. A case of adrenal Cushing's syndrome with bilateral adrenal masses. Endocrinol Diabetes Metab Case Rep. 2016;2016:15-0118.

35. Young WF, Stanson AW, Thompson GB, Grant CS, Farley DR, van Heerden JA. Role for adrenal venous sampling in primary aldosteronism. Surgery. 2004;136(6):1227-35.

36. Rossi GP, Barisa M, Allolio B, Auchus RJ, Amar L, Cohen D, et al. The Adrenal Vein Sampling International Study (AVIS) for identifying the major subtypes of primary aldosteronism. J Clin Endocrinol Metab. 2012;97(5):1606-14.

37. Daunt N. Adrenal vein sampling: how to make it quick, easy, and successful. Radiographics. 2005;25(Suppl 1):S143-58.

38. lihara M, Suzuki R, Kawamata A, Omi Y, Kodama H, Igari Y, et al. Adrenalpreserving laparoscopic surgery in selected patients with bilateral adrenal tumors. Surgery. 2003:134(6):1066-72. discussion 1072-73

39. Li ZH, Yu XY, Zhu YY, Zhang YX, Kong CZ. Steroid replacement therapy following adrenalectomy in patients with Cushing syndrome. J China Med Uni. 2010;39(06):476-7.

40. Ritzel K, Beuschlein F, Mickisch A, Osswald A, Schneider HJ, Schopohl J, et al. Clinical review: outcome of bilateral adrenalectomy in Cushing's syndrome: a systematic review. J Clin Endocrinol Metab. 2013;98(10):3939-48.

\section{Ready to submit your research? Choose BMC and benefit from:}

- fast, convenient online submission

- thorough peer review by experienced researchers in your field

- rapid publication on acceptance

- support for research data, including large and complex data types

- gold Open Access which fosters wider collaboration and increased citations

- maximum visibility for your research: over $100 \mathrm{M}$ website views per year 